\title{
Inti (Hymenoptera: Eulophidae) a peculiar new genus from tropical America
}

\author{
CHRISTER HANSSON \\ Rådmansgatan 13B, Lund, Sweden; Scientific Associate of the Entomology Department, the Natural History Museum, London, U.K.;
} e-.mail: christerdennis@gmail.com

\begin{abstract}
Inti gen. nov. (Hymenoptera: Eulophidae: Entedoninae), is described from Costa Rica and the Dominican Republic, and includes one new species, I. levis sp. nov. The new genus is characterized by four autapomorphies, and the possession of an additional 14 synapomorphies. Inti is compared to the Australian genus Horismenoides Girault with which it shares the most apomorphies, indicating a possible sister-group relationship. The relationship of Inti to the tribe Euderomphalini and to other groups in the subfamily is discussed briefly.
\end{abstract}

Key words: Entedoninae, Euderomphalini, Horismenoides, neotropics, taxonomy

\section{Introduction}

The fauna of Eulophidae in tropical America has had several contributions during the last decade, with the addition of several hundreds of new species, which have added considerably to the information on the diversity of the morphology, biology and distribution of this group. Despite these contributions many new taxa from this region remain undescribed and are thus unable to inform hypotheses on the classification and relationships of this group. To add to the knowledge of Eulophidae in tropical America, and to the group in general, an enigmatic new genus including a single new species with a unique combination of characters is described here. Currently there is no genus from tropical America that shows any resemblance to this new genus, here given the name Inti.

\section{Morphological abbreviations and acronyms}

Abbreviations of morphological terms: $\mathrm{HE}=$ height of eye; $\mathrm{HW}=$ height of wing, measured across widest part of wing; $L G=$ length of gaster; $\mathrm{LM}=$ length of marginal vein; $\mathrm{LW}=$ length of wing, measured from base of marginal vein to apical margin of wing; $\mathrm{MM}=$ length of mesosoma; $\mathrm{MO}=$ mouth opening; $\mathrm{MS}=$ malar space, i.e. distance between lower margin of eye and mouth opening; $\mathrm{OOL}=$ distance between eye and posterior ocellus; $\mathrm{PM}=$ length of postmarginal vein; $\mathrm{POL}=$ distance between posterior ocelli; $\mathrm{POO}=$ distance between posterior ocelli and occipital margin; ST = length of stigmal vein; WH = width of head; WT = width of thorax, measured across widest part which is usually just in front of attachment point of forewing. For illustrations of the morphological terms see www.neotropicaleulophidae.com.

Acronyms of museums used in the text are as follows: $\mathrm{BMNH}=$ The Natural History Museum, London; CNC $=$ Canadian National Collection of Insects, Arachnids and Nematodes, Ottawa; INBio = Instituto Nacional de Biodiversidad, Santo Domingo, Costa Rica.

\section{Inti Hansson gen. nov.}

Type species: Inti levis sp. nov., designated here. 
Etymology. Named after Inti, the Inca deity of the sun. Name referring to the circular, and thus sun-shaped, female gaster. The gender is masculine.

Diagnosis. Head and body smooth and shiny, without reticulation (Figs 2, 4-6, 8-10); frons with upper part of interscrobal surface protruding up and over frontal suture (Fig. 2); frontal suture smoothly arcuate (Fig. 2); vertex and upper frons close to eye margin with a groove (Figs 2,4); antennal scrobes as narrow and distinct grooves (Fig. 2); scape and pedicel compressed and wide, and pedicel with a dorsal edge (Figs 2, 3); flagellomeres with upper surface of longitudinal sensilla (= multiporous plate sensilla) concave (Fig. 3); pronotum reduced and hardly visible in dorsal view (Fig. 6); pair of setae on midlobe of mesoscutum and scutellum stout (Fig. 6); midlobe of mesoscutum with one pair of setae (Fig. 6); notauli as deep and narrow grooves in posterior 2/3, terminating just before transscutal articulation and with a fovea in very anterior part (Fig. 6); sidelobe of mesoscutum with a small hole centrally (Fig. 6) and with margin between dorsal and lateral parts as a sharp carina (Fig. 5); anterior part of mesepisternum protruding into posterior part of prepectus (Fig. 5); border between upper and lower mesepisternum developed as a sharp carina (Fig. 5); propodeum with callus posterior to spiracle drawn out to a sharp point (Fig. 6); propodeum with wide median carina (Fig. 6); forewing with basal 1 1/2 bare (Fig. 1); gaster subsessile, round (Figs 1, 8).

Description. Head smooth and shiny (Figs 2, 4). Female flagellum (Fig. 3) with a 3-segmented clava; sensilla ampullacea short and asymmetric (type II sensu Hansson (1990)), present on all flagellomeres, and with prominent elongate sensilla on each flagellomere; with two very small anelli. Scape distinctly compressed in female (Fig. 3), reaching above frontal suture; pedicel with a sharp edge along dorsal margin. Mandible with two large teeth apically and with a row of small teeth above large teeth. Clypeus not delimited (Fig. 2). Tentorial pits not visible (Fig. 2). Malar sulcus present (Fig. 2). Frons (Fig. 2) with interscrobal area protruding upwards and covering median part of frontal suture; frontal suture smoothly curved, close to eyes strongly curved upwards. Upper frons with a groove close to eye margin that continues dorsally on vertex (Figs 2, 4). Border between vertex and occiput with a sharp margin (Fig. 4); occiput without a median groove or fold between occipital margin and occipital foramen.

Mesosoma smooth and shiny (Fig. 6). Pronotum reduced, visible as a narrow strip in dorsal view (Fig. 6). Sidelobe of mesoscutum with margin between dorsal and ventral parts as a sharp carina (Figs 5, 6). Notauli (Fig. 6) starting with a small round fovea anteriorly, as deep and narrow grooves in posterior $2 / 3$, and terminating just before transscutal articulation. Midlobe of mesoscutum with one pair of setae; scutellum with one pair of setae situated in posterior half of scutellum (Fig. 6). Axillae with anterior $1 / 2$ strongly convex (Figs 1, 6). Dorsellum short and wide, with a deep groove interrupted by longitudinal carinae in anterior $1 / 2$ (Fig. 6). Pleurae (Fig. 5) with very weak reticulation; border between upper and lower mesepisternum carinate; anterior part of mesepisternum protruding into posterior part of prepectus; transepimeral sulcus (i.e. sulcus separating upper and lower mesepimeron) a straight and very wide and indistinct groove. Propodeum (Figs 1,6) with a wide concave median carina that widens towards posterior part; median area delimited laterally by wide grooves; part behind spiracles drawn out to a posteriorly projecting point; propodeal callus with three setae. Forewing (Fig. 1) with basal 1/2 bare; costal cell narrow, as wide as submarginal vein; postmarginal vein $0.3 \mathrm{X}$ as long as stigmal vein.

Petiole very small, not visible in type specimens. Gaster (Figs 1,7) almost circular; first tergite short, covering about $1 / 8$ of gaster.

Identification. In the key to the Nearctic genera of Eulophidae by Schauff et al. (1997) Inti runs to couplet 106, subfamily Entedoninae, and from there females can be separated from those of all other world genera by the four autapomorphies listed in the discussion below. Another option for identification is to use the matrix key to the Neotropical genera of Entedoninae on the website www.neotropicaleulophidae.com.

\section{Inti levis sp. nov.}

(Figs 1-10)

Diagnosis. See diagnostic characters for genus above.

Description. FEMALE. Length 1.3-1.5 mm. Antenna black with purple tinges. Frons and vertex (Figs 8, 9) black with metallic purple, blue and green tinges. Mesoscutum, scutellum and propodeum (Figs 8, 10) black to dark brown with metallic tinges. Coxae, femora and tibiae black with metallic tinges, tarsomeres 1-3 yellowishwhite, tarsomere 4 black. Forewing hyaline with a fuscous band medially, reaching from fore margin to hind mar- 
gin of wing (Fig. 1), hind wing hyaline. Petiole black with metallic tinges. Gaster black to brown with metallic purple and blue tinges, $6^{\text {th }}$ tergite metallic blue.

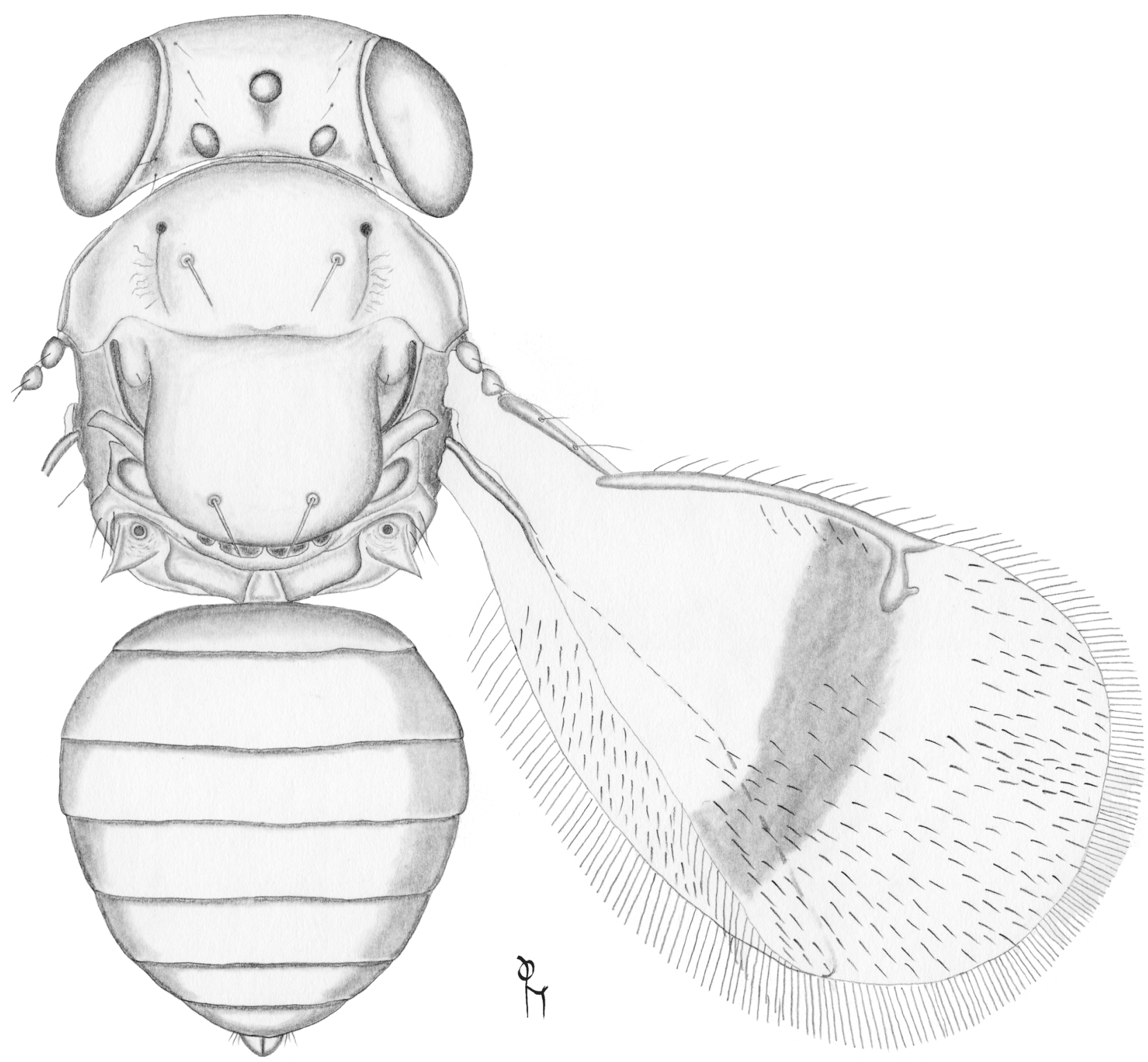

FIGURE 1. Inti levis sp. nov., female holotype, body length $1.5 \mathrm{~mm}$.

For remaining description see the above description for the genus.

Ratios. HE/MS/MO = 3.1/1.0/1.8; POL/OOL/POO = 34.0/13.0/1.0; WH/WT = 1.1; LW/LM/HW = 2.0/1.0/ $1.3 ; \mathrm{PM} / \mathrm{ST}=0.3 ; \mathrm{MM} / \mathrm{LG}=1.0$.

MALE. Unknown.

Material examined. Holotype female (BMNH) labelled "COSTA RICA, Cartago, Humo, El Copál, 947’N

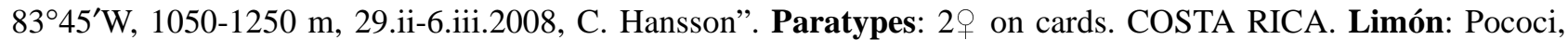
Parque Nacional Braulio Carrillo, Estacion Quebrada Gonzales, 4-500 m, 23-30.iii.2002, LN238380/543100, P. Hanson \& C. Godoy (1 , INBio). DOMINICAN REPUBLIC. Barahona, 4 km N. Paraiso, 22.iii.1991, 150 m, L. Masner" $(1$,, $\mathrm{CNC})$.

Etymology. Name referring to the smooth and shiny body, from the Latin levis = smooth.

Distribution. Northern Neotropical region (Costa Rica, Dominican Republic).

Biology. Unknown. 


\section{Discussion}

Inti is a peculiar genus of the Neotropical fauna of the subfamily Entedoninae. It is firmly established through four autapomorphies. The remaining apomorphies of Inti are also present in other entedonine genera, in a more or less mosaic pattern as listed below:

\section{Autapomorphies of Inti}

frons with upper part of interscrobal surface protruding up and over frontal suture (Fig. 2)

notaular grooves with a fovea in very anterior part (Fig. 6)

sidelobe of mesoscutum with a small hole centrally (Fig. 6)

border between upper and lower mesepisternum developed as a sharp carina (Fig. 5)

Synapomorphies shared only with Horismenoides Girault

frontal suture smoothly curved into a double arch (Fig. 2)

sidelobe of mesoscutum with margin between dorsal and lateral parts developed as a sharp carina (Fig. 5)

Synapomorphies for Horismenoides not present in Inti:

malar sulcus absent; the malar sulcus is usually present throughout the Eulophidae but has occasionally been lost in all subfamilies, in Entedoninae it has been lost in e.g. some species of Emersonella Girault, Paracrias Ashmead and Pediobius Walker (Hansson 2002)

- pair of setae on midlobe of mesoscutum and scutellum very short and thin; this is a different apomorphic state from the short and stout setae in

Inti, both are derived from long and moderately thick setae present in most Entedoninae

axillae strongly advanced forward; also present in tribe Euderomphalini (La Salle \& Schauff 1994)

mesoscutum with a complete median groove; also present in some other Entedoninae genera, e.g. Parzaommomyia Girault (Bouček 1988)

Synapomorphies shared with some other entedonine genera, and with Horismenoides

antennal scrobes as narrow and distinct grooves (Fig. 2); also present in many other entedonine genera, e.g. Horismenus Walker (Hansson 2009a) and Paracrias (Hansson 2002)

pronotum reduced and hardly visible in dorsal view (Fig. 6); also present in several other entedonine genera, e.g. Omphale Haliday (Hansson 2004)

midlobe of mesoscutum with one pair of setae (Fig. 6); also present in several other entedonine genera, e.g. Chrysonotomyia Ashmead (Hansson 2004) and some Closterocerus Westwood (Hansson 1994)

head and body smooth and shiny, without reticulation (Figs 2, 4-6, 8-10); also present in Oradis Hansson (Hansson 2002)

forewing with basal $1 / 2$ bare (Fig. 1); also present in some species of Paracrias (Hansson 2002) and Klyngon Hansson (Hansson \& La Salle 2010)

Synapomorphies shared with some other entedonine genera, but not with Horismenoides

vertex and upper frons with a groove running along eye margin (Figs 2, 4); a similar groove is present in many species of Emersonella (Hansson 2002)

scape and pedicel compressed, and pedicel with a dorsal edge (Fig. 3); also present in Closterocerus s. str. (Hansson 1994)

flagellomeres with upper surface of longitudinal sensilla (= multiporous plate sensilla) concave (Fig. 3); also present in Horismenus and Microdonophagus Schauff (Hansson 2009b)

pair of setae on midlobe of mesoscutum and scutellum stout (Fig. 6); a similar state is present in some species of Astichomyiia Girault (Hansson 2002) and Chrysonotomyia (Hansson 2004).

notauli as deep and narrow grooves in posterior $2 / 3$ that terminate just before transscutal articulation (Fig. 6); a similar state is present in Eprhopalotus Girault (Schauff 1991, as Aabacharis Schauff)

anterior part of mesepisternum protruding into posterior part of prepectus (Fig. 5); also present in Horismenus (Hansson 2009a) and some species of Pediobius (Hansson 2002)

propodeum with callus posterior to spiracle drawn out to a sharp point (Fig. 6); a similar state is present in some genera of the tribe Euderomphalini (Entedononecremnus Girault, Itahipeus Hansson \& La Salle, and Sifraneurus Hansson \& La Salle) (Hansson \& La Salle 2003) 
Other diagnostic features of uncertain polarity for Inti: propodeum with a wide median carina (Fig. 6), also present in Horismenoides gaster subsessile, almost round (Figs 1,8), also present in Horismenoides

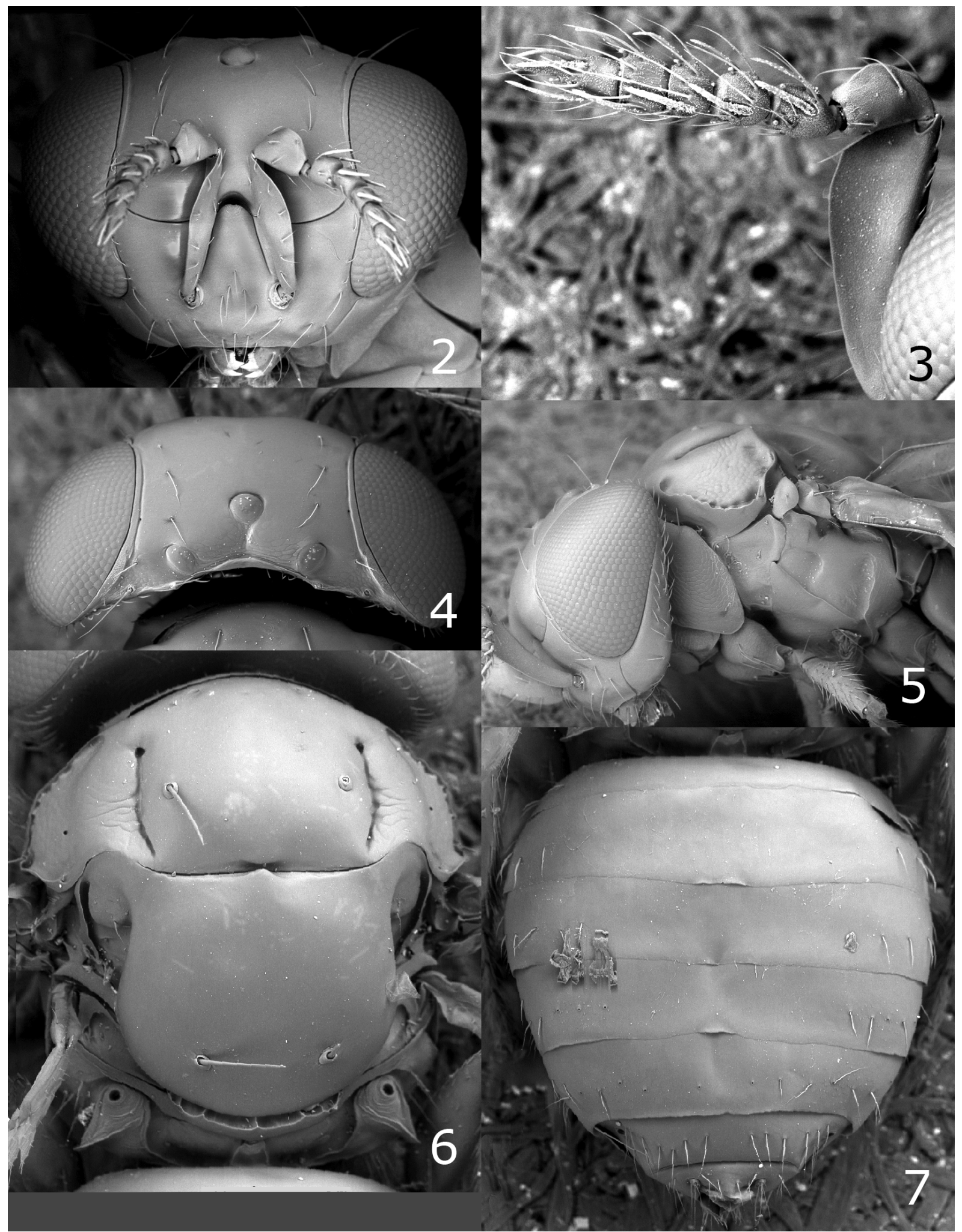

FIGURES 2-7. Inti levis sp. nov., female. 2. Head frontal. 3. Antenna lateral. 4. Head dorsal. 5. Head and mesosoma lateral. 6. Mesosoma dorsal. 7. Gaster dorsal. 
The above list of apomorphic and diagnostic features shows that Inti shares most apomorphies with the Australian genus Horismenoides and it is possible that they are sister groups. Bouček (1988), in his treatment of Horismenoides, stated that it may be related to Baeoentedon Girault and Euderomphale Girault, both belonging in tribe Euderomphalini (La Salle \& Schauff 1994). La Salle \& Schauff (1994) also speculated on the placement of Horismenoides in the Euderomphalini, but made no decisive remark about its affiliation. The propodeum in Inti is drawn out to a sharp point behind the spiracle (Fig. 6), an apomorphy present also in some genera of the Euderomphalini (see above), which may also indicate a placement in this tribe. However, the fact that the axillae in Inti are not strongly advanced forward (which is a key feature for Euderomphalini) and the possession of other apomorphies not present in Euderomphalini may suggest other affinities. For instance, flagellomeres having the upper surface of the longitudinal sensilla concave and the anterior part of the mesepisternum protruding into the posterior part of the prepectus may suggest a relationship with Horismenus, whereas the groove along the eye on vertex and upper frons may suggest a relationship with Emersonella. Because of this mosaic possession of derived characters I do not presently classify Inti in either Euderomphalini or in Entedonini (to which Horismenus and Emersonella belong), but leave it unplaced until further information becomes available.

No material of Horismenoides has been examined, features mentioned here are from the redescription and illustrations in Bouček (1988) and La Salle \& Schauff (1994).

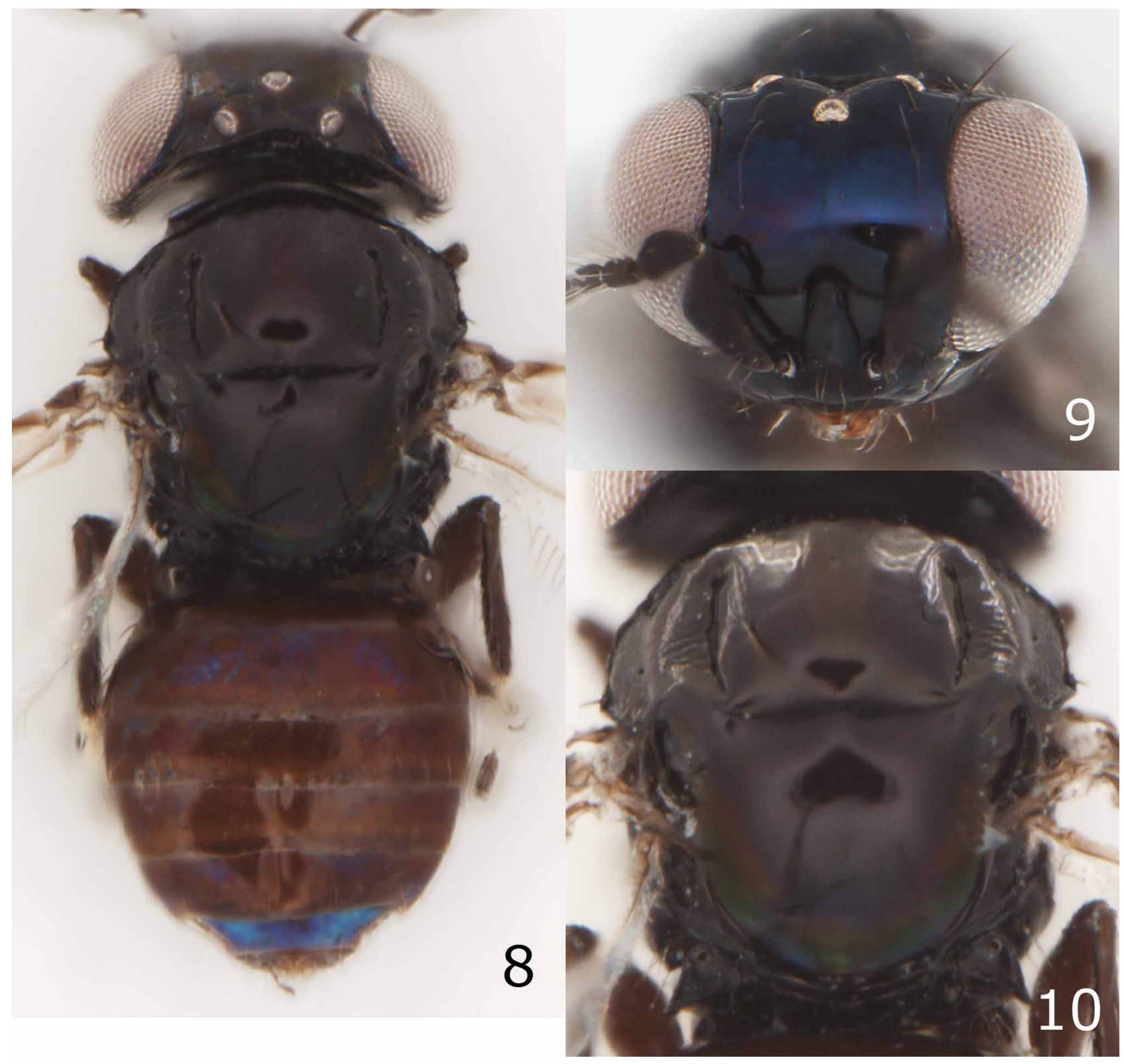

FIGURES 8-10. Inti levis sp. nov., female. 8. Body dorsal. 9. Head frontal. 10. Mesosoma dorsal. 


\section{Acknowledgements}

Acknowledgements are due to CNC (through Dr. John La Salle, currently at the Australian National Insect Collection) and INBio for loan of material, to the Department of Biology, Lund University for the use of their SEM facility, and to two anonymous reviewers for valuable comments on the manuscript.

\section{References}

Bouček, Z. (1988) Australasian Chalcidoidea (Hymenoptera): A biosystematic revision of fourteen families, with a reclassification of species. CAB International, Wallingford, U.K. 832 pp.

Hansson, C. (1990) A taxonomic study on the Palearctic species of Chrysonotomyia Ashmead and Neochrysocharis Kurdjumov (Hymenoptera, Eulophidae). Entomologica Scandinavica, 20, $29-52$.

Hansson, C. (1994) Re-evaluation of the genus Closterocerus Westwood (Hymenoptera, Eulophidae), with a revision of the Nearctic species. Entomologica Scandinavica, 25, 1-25.

Hansson, C. (2002) Eulophidae of Costa Rica, 1. Memoirs of the American Entomological Institute, 67, 1-290.

Hansson, C. (2004) Eulophidae of Costa Rica, 2. Memoirs of the American Entomological Institute, 75, 1-536.

Hansson, C. (2009a) Eulophidae of Costa Rica, 3. Memoirs of the American Entomological Institute, 82, 1-916.

Hansson, C. (2009b) The genus Microdonophagus Schauff (Hymenoptera: Eulophidae), with description of a new species. Zootaxa, 2200, 54-60.

Hansson, C. \& La Salle, J. (2003) Revision of the Neotropical species of the tribe Euderomphalini (Hymenoptera: Eulophidae). Journal of Natural History, 37, 697-778.

Hansson, C. \& La Salle, J. (2010) The Neotropical genus Klyngon Hansson (Hymenoptera: Eulophidae), with new species and biological information. Zootaxa, 2498, 1-27.

La Salle, J. \& Schauff, M.E. (1994) Systematics of the tribe Euderomphalini (Hymenoptera: Eulophidae): parasitoids of whiteflies (Homoptera: Aleyrodidae). Systematic Entomology, 19, 235-258.

Schauff, M.E. (1991) The Holarctic genera of Entedoninae (Hymenoptera: Eulophidae). Contributions of the American Entomological Institute, 26(4), 1-109.

Schauff, M.E., La Salle, J. \& Coote, L.D. (1997) Eulophidae. Pp 327-429, in Gibson, G.A.P., Huber, J.T. \& Woolley, J.B. (eds.), Annotated Keys to the Genera of Nearctic Chalcidoidea (Hymenoptera). National Research Council Research Press. Ottawa, Ontario, Canada. 794 pp. 